\title{
Quality of Life of Primary Caregivers Attending a Rural Cancer Centre in Western Maharashtra: A Cross-Sectional Study
}

\author{
Shubham S. Kulkarni ${ }^{1} \quad$ Chaitanya R. Patil ${ }^{2} \quad$ Yogesh S. Anap ${ }^{3}$ Prasad K. Tanawade ${ }^{3}$ Parag J. Watve ${ }^{4}$ \\ Aditya S. Pawar ${ }^{5}$
}
${ }^{1}$ Department of Palliative Care, Kolhapur Cancer Centre, Kolhapur, Maharashtra, India
${ }^{2}$ Department of Pain and Palliative Care, Kolhapur Cancer Centre, Kolhapur, Maharashtra, India
${ }^{3}$ Department of Radiation Oncology, Kolhapur Cancer Centre, Kolhapur, Maharashtra, India
${ }^{4}$ Department of Head and Neck Surgery, Kolhapur Cancer Centre, Kolhapur, Maharashtra, India
${ }^{5}$ Department of Medical Oncology, Kolhapur Cancer Centre,
Kolhapur, Maharashtra, India

\begin{abstract}
Address for correspondence Chaitanya Patil, MBBS, MD, PDF in Palliative Care, Consultant Pain and Palliative Care, Kolhapur Cancer Centre, Kolhapur 416234, Maharashtra, India (e-mail: docterchaitanya@gmail.com).
\end{abstract}

Ind J Med Paediatr Oncol 2021;42:268-272.

\section{Abstract}

\section{Keywords}

- primary caregiver

- cancer

- quality of life

- rural India
Introduction Caregiver plays a vital role in taking good care of a cancer patient. But often, the caregiver's quality of life (QOL) is overlooked.

Objectives This study aimed to understand the Caregiver QOL Index-Cancer (CQOL-C) score of the primary caregivers and to find the significant predictors affecting CQOL-C.

Materials and Methods A cross-sectional study was conducted among the caregivers attending a rural cancer center in western Maharashtra. The primary caregiver is an immediate relative who assists the patient in most routine activities and is not a professional caregiver. A pretested and predesigned questionnaire using the CQOL-C scale was used to interview the caregivers from December 2019 to June 2020. We analyzed the data using Statistical Package of Social Sciences (SPSS) software. Univariate analysis was done using Student's $t$-test and a multivariate model was generated using linear regression analysis of the data.

Results A total of 114 caregivers were interviewed. The mean total CQOL-C score was $44.15 \pm 17.24$ (confidence interval [Cl]: $41-47.3$ ). About $71 \%$ of the caregivers reported moderate-to-severe hampering of their QOL. The mean CQOL-C scores in caregivers of patients with and without recurrent cancer were 58.24 (Cl: 51.66-64.81) and 40.58 ( $\mathrm{Cl}: 37.35-43.80)$, respectively $(p<0.001)$. The mean CQOL-C scores in caregivers of patients with and without metastatic cancer were $56.68(\mathrm{Cl}: 51$. 13-62.22) and 39.80 ( $\mathrm{Cl}: 36.45-43.14)$, respectively $(p<0.001)$. The mean CQOL-C score in caregivers of patients with hematological malignancies was 60.03 (Cl: 58.88 61.17 ) which was significantly higher compared with other sites $(p=0.0257)$.

Conclusion The majority of the caregivers in our study have moderate-to-severe detrimental QOL. Recurrence of cancer and metastatic cancer at presentation are the two significant factors affecting CQOL-C. There is an unmet need to cater to the primary caregiver's concerns while we focus on treating cancer patients.
DOI https://doi.org/

$10.1055 / \mathrm{s}-0041-1735664$

ISSN 0971-5851
(C) 2021. Indian Society of Medical and Paediatric Oncology.

This is an open access article published by Thieme under the terms of the Creative Commons Attribution-NonDerivative-NonCommercial-License, permitting copying and reproduction so long as the original work is given appropriate credit. Contents may not be used for commercial purposes, or adapted, remixed, transformed or built upon. (https://creativecommons.org/licenses/by-nc-nd/4.0/).

Thieme Medical and Scientific Publishers Private Ltd. A-12, Second

Floor, Sector -2, NOIDA -201301, India 


\section{Introduction}

Cancer is one of the most feared and dreaded chronic diseases across the world. ${ }^{1}$ The patient spends more time at home as compared with the cancer center during this prolonged treatment duration, often spanning from months to years. ${ }^{2-4}$ In rural India, majority of the people still live in joint families. Diagnosis of cancer in a family member enforces the family to put efforts collectively to help the patient. ${ }^{5}$ The socioeconomic conditions in rural India do not permit hiring a professional caregiver, and hence, it becomes mandatory to take the role of "primary caregiver" by spouse, sibling, or children. ${ }^{6}$

The primary caregiver is involved in monitoring the changes in the patient's condition, making decisions, providing hands-on care, making adjustments, accessing resources, negotiating with health care system, emotional support, and often arranging funds for the treatment. ${ }^{7}$ Balancing the cancer patient's care with his or her own personal routine is a challenging task, physically and emotionally, to the primary caregiver. ${ }^{8,9}$ Caregiving from historical times has been regarded as a meaningful experience but the sequelae of the caregivers is often overlooked. ${ }^{8}$ At Kolhapur Cancer Centre which is a rural cancer center in western India, we have reported approximately 3,000 new cancer patients in a year with two out of three patients presenting with either stage III or stage IV. ${ }^{10}$ The Caregiver Quality of Life Index-Cancer (CQOL-C) scale is a measure of effect of the illness of the cancer patient on the caregiver's physical, emotional, social, family, and other areas of functioning. The total score ranges from 0 to 140. The higher the score, the worse is the CQOL-C. ${ }^{11}$ There is paucity of data over the CQOL-C in rural India. Hence, we conducted this study to understand the score of the primary caregivers and to find the significant predictors affecting it, attending Kolhapur Cancer Centre, India.

\section{Materials and Methods}

This cross-sectional study was conducted among the primary caregivers of cancer patients attending our center. Primary caregiver was an immediate relative who is assisting the patient in most routine activities and is not a professional caregiver. The duration of the study was from December 2019 to June 2020. The 114 caregivers were selected by convenience sampling. All the primary caregivers were above 18 years of age. The minimum duration between the date of cancer diagnosis and the interview of caregiver was 3 months.

A pretested and predesigned questionnaire adapted from current literature was used to interview the caregivers. ${ }^{11}$ The questionnaire had two parts. The first part included the age, gender, site of cancer, Eastern Cooperative Oncology Group (ECOG) status of the patient, relationship with the caregiver, age of caregiver, gender of caregiver, presence of metastases, and whether it was new or recurrent cancer case. The second part consisted of the CQOL-C scale. ${ }^{11}$ It had 35 QOL specific items each graded from 0 to 4 on Likert's scale of which "0" was "Not at all," "1" was "A little bit," "2" was "Somewhat," "3" was "Quite a bit," and "4" was "Very much." Question numbers $10,12,16,22,27,28$, and 34 were reverse graded and analyzed. Question number 4 in the scale was omitted from the analysis due to missing data. A total score was obtained by adding all the 34 items and final score was considered for analysis.

The scale was translated to Marathi language by two independent translators and a final approved version was used to collect the data. Data were collected by interviewing the caregivers in person. A pilot study was conducted among 10 caregivers to finalize the questionnaire. This pilot also revealed the standard deviation of total CQOL-C score to be 16.23 . Using this, with $95 \%$ confidence interval (CI) and 3.5\% error, we found the minimum sample size to be $86 .{ }^{12}$ For our convenience, we included all 114 interviewed caregivers in the present study.

\section{Statistical Analysis}

The data were collected and compiled in Microsoft Excel. The data were analyzed using statistical package of social sciences (SPSS) version 20.00. The data were coded and analyzed using the guidelines published by the Measurement Instrument Database for Social Sciences (MIDSS). ${ }^{13}$ The qualitative variables were expressed in terms of percentages. Quantitative variables were expressed in terms of mean and their 95\% CIs. The total score of CQOL-C was categorized based on the quartiles of our dataset into less than 30 , 30 to 60 , and more than 60 and then expressed in terms of percentages. To test the difference between 2 means, Student's $t$-test was used and more than 2 means, analysis of variance (ANOVA) was used. Univariate analysis was done for all the factors and those factors which had $p$-value of $<0.10$ included in multiple linear regression analysis. Normality of the data were tested using probability plots. Linearity of the factors was tested using scatter diagrams. The independence was tested using Dubin-Watson test. After all these assumptions were met, stepwise method of multiple linear regression analysis was used to find the significant predictors which affect the CQOL-C. The best model fit was determined and $R^{2}$ statistics was reported for the model. All of them were two-tailed analyses and the significance was set at 0.05 .

\section{Ethics}

Kolhapur Cancer Center institutional ethics committee (ECR-/523/INST/MH/2014/RR-17, dated December 16, 2019) approval for the study was obtained. Written informed consent was taken from all the participants with precautions to maintain the confidentiality. The procedures followed were in accordance with the ethical standards of the responsible committee on human experimentation and with Helsinki Declaration of 1964, as revised in 2013.

\section{Results}

We included a total of 114 primary caregivers in the present study. The mean age of the caregivers was $40.75 \pm 11.45$ years 
with male preponderance (male:female $=1.32: 1$ ). Majority of the primary caregivers were related as children (50.86\%) of the cancer patients. The proportion of recurrent cancer and metastatic cancer at the time of interview were 20.18 and $25.44 \%$, respectively. More than half of the patients had an ECOG performance score of 3 or 4 (-Table 1 ).

Head and neck (47.37\%) was the most common site of cancer in the present study ( - Fig. 1).

The mean total CQOL-C score was $44.15 \pm 17.24$ (CI: 41-47.3) with $71.05 \%$ of the caregivers having moderate-to-severe hampering of their QOL (-Table 2). The mean CQOL-C scores in caregivers of patients with and without recurrent cancer were 58.24 (CI: 51.66-64.81) and 40.58 (CI: 37.35-43.80), respectively $(p<0.001)$. The mean CQOL-C scores in caregivers of patients with and without metastatic cancer were 56.68 (CI: 51.13-62.22) and 39.80 (CI: $36.45-43.14)$, respectively $(p<0.001)$. The mean CQOL-C scores in caregivers of patients with hematological malignancies was 60.03 (CI: 58.88-61.17) which was significantly higher compared with other sites $(p=0.0257$; - Table 3). Stepwise linear regression analysis showed the presence of recurrence and metastases in patients were significant predictors affecting the primary caregivers' CQOL-C score (-Table 4).

Table 1 Demographic particulars of the participants

\begin{tabular}{|c|c|c|}
\hline Demographic particulars & Frequency & Percentage \\
\hline \multicolumn{3}{|l|}{ Age of the caregiver (y) } \\
\hline$<30$ & 19 & 16.67 \\
\hline 31 to 40 & 34 & 29.82 \\
\hline 41 to 50 & 30 & 26.32 \\
\hline 51 to 60 & 22 & 19.30 \\
\hline$>60$ & 9 & 7.89 \\
\hline \multicolumn{3}{|l|}{ Gender of caregiver } \\
\hline Female & 49 & 42.98 \\
\hline Male & 65 & 57.02 \\
\hline \multicolumn{3}{|l|}{ Relation with patient } \\
\hline Children & 58 & 50.88 \\
\hline Spouse & 43 & 37.72 \\
\hline Sibling & 9 & 7.89 \\
\hline Parents & 4 & 3.51 \\
\hline \multicolumn{3}{|l|}{ Recurrence } \\
\hline Yes & 23 & 20.18 \\
\hline No & 91 & 79.82 \\
\hline \multicolumn{3}{|l|}{ Metastasis } \\
\hline Yes & 29 & 25.44 \\
\hline No & 85 & 74.56 \\
\hline \multicolumn{3}{|l|}{ ECOG } \\
\hline $0-2$ & 55 & 48.24 \\
\hline $3-4$ & 59 & 51.75 \\
\hline
\end{tabular}

Abbreviation: ECOG, the Eastern Cooperative Oncology Group.
Table 2 Distribution of the total CQOL-C score

\begin{tabular}{|l|l|l|}
\hline CQOL-C score & Frequency & Percentage \\
\hline $0-30$ (mild) & 33 & 28.95 \\
\hline 30-60 (moderate) & 67 & 58.77 \\
\hline 60-136 (severe) & 14 & 12.28 \\
\hline Total & 114 & 100.00 \\
\hline Mean & 44.15 & \\
\hline SD & 17.24 & \\
\hline
\end{tabular}

Abbreviations: CQOL-C, caregiver quality of life index-cancer; SD, standard deviation.

Table 3 Univariate analysis of the different parameters affecting CQOL-C

\begin{tabular}{|c|c|c|}
\hline \multirow[t]{2}{*}{ Parameters } & \multicolumn{2}{|c|}{ CQOL-C } \\
\hline & Mean & $\begin{array}{l}\text { Confidence } \\
\text { interval }\end{array}$ \\
\hline \multicolumn{3}{|l|}{ Age (y) } \\
\hline$<40$ & 43.34 & $39.08-47.59$ \\
\hline$>40$ & 45.18 & $40.40-49.95$ \\
\hline$p$-Value & 0.5723 & \\
\hline \multicolumn{3}{|l|}{ Gender } \\
\hline Female & 45.96 & $42.02-49.91$ \\
\hline Male & 41.74 & $36.60-46.87$ \\
\hline$p$-Value & 0.2054 & \\
\hline \multicolumn{3}{|l|}{ Relation with patient } \\
\hline Children & 45.22 & $40.38-50.05$ \\
\hline Spouse & 42.61 & $37.69-47.52$ \\
\hline Sibling & 42.00 & $33.25-50.74$ \\
\hline Parents & 50.00 & $39.81-60.18$ \\
\hline$p$-Value & 0.7659 & \\
\hline \multicolumn{3}{|l|}{ Recurrence } \\
\hline Yes & 58.24 & $51.66-64.81$ \\
\hline No & 40.58 & $37.35-43.80$ \\
\hline$p$-Value & $<0.001$ & \\
\hline \multicolumn{3}{|l|}{ Metastasis } \\
\hline Yes & 56.68 & $51.13-62.22$ \\
\hline No & 39.80 & $36.45-43.14$ \\
\hline$p$-Value & $<0.001$ & \\
\hline \multicolumn{3}{|l|}{ Site of cancer } \\
\hline Breast & 40.28 & $32.44-48.11$ \\
\hline Colorectal & 40.10 & $33.44-46.75$ \\
\hline Gynecology & 55.00 & $42.57-67.42$ \\
\hline Hematological & 60.03 & $58.88-61.17$ \\
\hline Head, face, and neck & 42.26 & $37.79-46.73$ \\
\hline Others & 51.83 & $38.57-65.07$ \\
\hline$p$-Value & 0.0257 & \\
\hline
\end{tabular}

Abbreviation: CQOL-C, caregiver quality of life index-cancer. 
Table 4 Stepwise multiple linear regression analysis of the different parameters affecting CQOL-C

\begin{tabular}{|l|l|l|l|l|l|}
\hline Parameters & $\begin{array}{l}\text { Unstandardized beta } \\
(95 \% \mathrm{Cl})\end{array}$ & $\begin{array}{l}\text { Standard } \\
\text { error }\end{array}$ & Standardized beta & $t$-Value & $p$-Value \\
\hline Constant & $38.88(35.55-42.22)$ & 1.68 & & 23.11 & 0.000 \\
\hline $\begin{array}{l}\text { Metastasis (present/ } \\
\text { absent) }\end{array}$ & $11.88(4.34-19.38)$ & 3.79 & 0.301 & 3.12 & 0.002 \\
\hline $\begin{array}{l}\text { Recurrence (present/ } \\
\text { absent) }\end{array}$ & $11.09(2.93-19.26)$ & 4.12 & 0.259 & 2.69 & 0.008 \\
\hline
\end{tabular}

Abbreviations: $\mathrm{Cl}$, confidence interval; $\mathrm{CQOL}-\mathrm{C}$, caregiver quality of life index-cancer. Note: Adjusted $R^{2}=0.224$; Dubin-Watson $=2.21$.

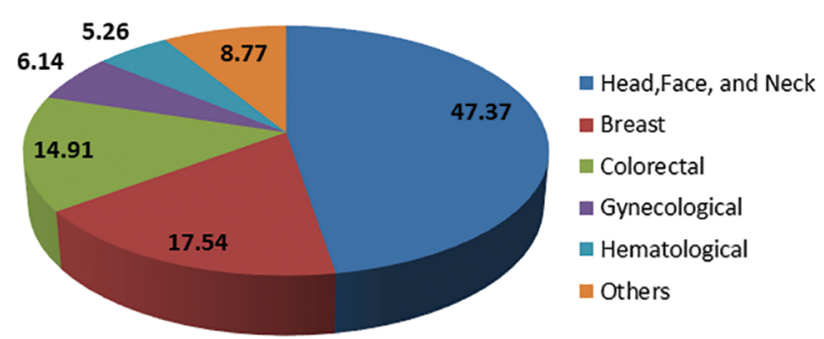

Fig. 1 Distribution based on the site of the malignancy.

\section{Discussion}

Treating a cancer patient is the most common service offered in a cancer center with little attention to the caregiver's needs. The QOL of caregivers of cancer patients is often a neglected part in routine practice. Improving the caregiver's QOL has a positive impact on the cancer patient's care. ${ }^{14,15}$ To highlight the importance of the QOL among the caregivers, we conducted a cross-sectional study to analyze CQOL-C in the patients attending a rural cancer hospital in western India.

There are numerous scales to quantify the caregiver's QOL like "the Caregiver Reaction Assessment," "Brief Assessment Scale for Caregivers," "Quality of Life in Life-Threatening Illness-Family Carer Version," "the Functional Assessment of Cancer Therapy Scale-General Format," "Measurement of Objective Burden and of Subjective Burden," "the Caregiver Strain Index," "Bakas' Caregiver Outcome Scale," and "the Caregiver Quality of Life Index-Cancer Scale."7 We chose the CQOL-C scale because it is a comprehensive assessment tool of physical, negative emotions, social, spiritual, and financial dimension of the primary caregiver of a cancer patient. The psychometric properties of the CQOL-C, such as internal consistency, test-retest reliability, content validity, and convergent validity, are well defined. ${ }^{7}$

The studies conducted in South East Asia and Middle Eastern countries which do share somewhat similar social norms and have reported higher CQOL-C score than the present study. ${ }^{16-23}$ Other studies conducted in the West revealed much higher CQOL-C as compared with the South East Asian and Middle Eastern studies. ${ }^{24-27}$ This reflects the role of societal norms and coping attitudes of caregivers of our region in providing the appropriate care along with handling their QOL.

The various factors affecting cancer caregivers QOL were gender, marital status, educational status, income status, insurance status, and relation of caregiver with patient reported in various studies. ${ }^{16-18}$ In the present study, the CQOL-C was significantly hampered in patients who had recurrence and metastasis. Other factors, like age of the caregiver, gender, site of cancer, and relationship of the caregiver with the patient, did not differ in their CQOLC scores. The primary caregiver experiences the natural course of the cancer patient from diagnosis, treatment initiation, treatment complications, treatment failure in terms of recurrence, decision to discontinue treatment and opting out for alternative treatment modalities, terminal illness, and death. ${ }^{7}$ Caregivers with recurrent cancer cases have poor QOL which might be due the shattering of the hope which was generated in the previous treatment modalities. The pain and suffering of metastatic cancer patients adversely affects the negative emotions of the primary caregiver. ${ }^{28}$ Higher symptom burden of the cancer patients, more economic strain, role changes during different modalities of treatment, loss of personal wages due to repeated visits to hospital, and family function disruption are some important cues which explain detrimental effects of CQOL-C among patients with metastatic disease at the time of interview. ${ }^{29-32}$

\section{Limitations and Strengths}

Our study had some limitations. It was a single-center study with smaller sample size. The follow-up of caregiver's QOL in the different phases of treatment modality was not addressed. There was no scope to intervene and assist the primary caregivers with significantly worst QOL. The future studies could be built on this knowledge to intervene in coping attitude of the primary caregiver. Nonetheless, this is one of the studies which has been conducted on caregiver's QOL in India and thus will add to the existing literature on the topic.

\section{Conclusion}

Majority of the caregivers in our study have moderate-to-severe detrimental QOL. Recurrence of cancer and metastatic cancer at presentation are the two significant factors affecting CQOL-C found in this study. There is unmet need to cater the primary caregivers' concerns while we focus on treating cancer patients.

\section{Funding}

None. 


\section{Conflict of Interest}

None declared.

\section{References}

1 Phillips JL, Currow DC. Cancer as a chronic disease. Collegian 2010;17(2):47-50

2 Tralongo P, Ferraù F, Borsellino N, et al. Cancer patient-centered home care: a new model for health care in oncology. Ther Clin Risk Manag 2011;7:387-392

3 Evans JM, Qiu M, MacKinnon M, Green E, Peterson K, Kaizer L. A multi-method review of home-based chemotherapy. Eur J Cancer Care Engl 2016;25(5):883-902

4 Smeenk FW, van Haastregt JC, de Witte LP, Crebolder HF. Effectiveness of home care programmes for patients with incurable cancer on their quality of life and time spent in hospital: systematic review. BMJ 1998;316(7149):1939-1944

5 Chadda RK, Deb KS. Indian family systems, collectivistic society and psychotherapy. Indian J Psychiatry 2013;55(2 suppl 2): S299-S309

6 Brinda EM, Rajkumar AP, Enemark U, Attermann J, Jacob KS. Cost and burden of informal caregiving of dependent older people in a rural Indian community. BMC Health Serv Res 2014;14(1):207

7 Grov EK, Dahl AA, Quality of life measures in caregivers of patients with cancer. In: Preedy VR, Watson RR, editors. Handbook of Disease Burdens and Quality of Life Measures. New York, NY: Springer New York; 2010 2935-2946

8 Schulz R, Sherwood PR. Physical and mental health effects of family caregiving. Am J Nurs 2008;108(9 suppl):23-27, quiz 27

9 Pérez-Sánchez IN, Rascón-Gasca ML, Villafaña-Tello Jde S. Coping and emotional discomfort in primary caregivers of cancer patients. Rev Invest Clin 2014;66(6):495-504

10 Tanawade P, Anap Y, Pawar R, Kapale I, Pawar S. Sociodemographic features of cancer patients registered at a single rural cancer hospital in Western India. Indian J Med Paediatr Oncol 2020;41(3):372-377

11 Weitzner MA, Jacobsen PB, Wagner H Jr, Friedland J, Cox C. The Caregiver Quality of Life Index-Cancer (CQOLC) scale: development and validation of an instrument to measure quality of life of the family caregiver of patients with cancer. Qual Life Res 1999;8(1-2):55-63

12 Kadam P, Bhalerao S. Sample size calculation. Int J Ayurveda Res 2010;1(1):55-57

13 Midss.org. [Internet]. The Caregiver Quality of Life Index-Cancer (CQOLC) scale. Available at: https://www.midss. org/content/caregiver-quality-life-index-cancer-cqolc-scale. Accessed July 2, 2020

14 El-Jawahri A, Greer JA, Pirl WF, et al. Effects of early integrated palliative care on caregivers of patients with lung and gastrointestinal cancer: a randomized clinical trial. Oncologist 2017;22(12):1528-1534

15 Kristanti MS, Setiyarini S, Effendy C. Enhancing the quality of life for palliative care cancer patients in Indonesia through family caregivers: a pilot study of basic skills training. BMC Palliat Care 2017;16(1):4
16 Thirumoorthy A, Devi PS, Thennarusu K. Quality of life among the caregivers of persons living with cancer. J Humanit Soc Sci 2016;21(2):23-30

17 Warapornmongkholkul A, Howteerakul N, Suwannapong N, Soparattanapaisarn N. Self-efficacy, social support, and quality of life among primary family-member caregivers of patients with cancer in Thailand. J Heal Res 2018;32(2):111-122

18 Lim HA, Tan JYS, Chua J, et al. Quality of life of family caregivers of cancer patients in Singapore and globally. Singapore Med J 2017;58(5):258-261

19 Turkoglu N, Kilic D. Effects of care burdens of caregivers of cancer patients on their quality of life. Asian Pac J Cancer Prev 2012;13(8):4141-4145

20 Son $\mathrm{KY}$, Lee $\mathrm{CH}$, Park SM, et al. The factors associated with the quality of life of the spouse caregivers of patients with cancer: a cross-sectional study. J Palliat Med 2012;15(2):216-224

21 Mahendran R, Lim HA, Chua J, Peh CX, Lim SE, Kua EH. The Caregiver Quality of Life Index-Cancer (CQOLC) in Singapore: a new preliminary factor structure for caregivers of ambulatory patients with cancer. Qual Life Res 2015;24(2):399-404

22 Hashemian M, Fallahi A, Hosseini VM, Asadi ZS, Soleimanian A. Evaluation of the quality of life of female family caregivers of patients with breast cancer in Iran (2013. J Midwifery Reprod Heal 2013;5(1):821-827

23 Vashistha V, Poulose R, Choudhari C, Kaur S, Mohan A. Quality of life among caregivers of lower-income cancer patients: a single-institutional experience in India and comprehensive literature review. Asian Pac J Cancer Care 2019;4(3):87-93

24 Shahi V, Lapid MI, Kung S, et al. Do age and quality of life of patients with cancer influence quality of life of the caregiver? J Geriatr Oncol 2014;5(3):331-336

25 Miguel I, Moreira A, Freire J. Burden, quality of life and distress of the main caregiver in head and neck, cervix and rectal cancer patients. J Cancer Res Ther 2017;5(3):14-18

26 Patterson JM, Rapley T, Carding PN, Wilson JA, McColl E. Head and neck cancer and dysphagia; caring for carers. Psychooncology 2013;22(8):1815-1820

27 Wadhwa D, Burman D, Swami N, Rodin G, Lo C, Zimmermann C. Quality of life and mental health in caregivers of outpatients with advanced cancer. Psychooncology 2013;22(2):403-410

28 Woźniak K, Iżycki D. Cancer: a family at risk. Przegl Menopauz 2014;13(4):253-261

29 Moreno-Smith M, Lutgendorf SK, Sood AK. Impact of stress on cancer metastasis. Future Oncol 2010;6(12):1863-1881

30 Takeuchi T, Ichikura K, Amano K, Takeshita W, Hisamura K. The degree of social difficulties experienced by cancer patients and their spouses. BMC Palliat Care 2018;17(1):83

31 Rajpal S, Kumar A, Joe W. Economic burden of cancer in India: Evidence from cross-sectional nationally representative household survey, 2014. PLoS One 2018;13(2):e0193320-e0193320

32 Kim Y, Yen IH, Rabow MW. Comparing symptom burden in patients with metastatic and nonmetastatic cancer. J Palliat Med 2016;19(1):64-68 